\title{
COVID-19 as an undesirable political issue: Conspiracy beliefs and intolerance of uncertainty predict adhesion to prevention measures
}

\author{
Jessica Farias ${ }^{1} \cdot$ Ronaldo Pilati $^{1}$ (D) \\ Accepted: 22 January 2021 / Published online: 2 February 2021 \\ (C) The Author(s), under exclusive licence to Springer Science+Business Media, LLC part of Springer Nature 2021
}

\begin{abstract}
Conspiracy theories thrive in moments of crises because they provide straightforward answers that assist individuals in coping with threats. The COVID-19 outbreak is such a crisis and is boosted by the political turmoil related to the politicization of the pandemic in some countries. To assess the role of political partisanship, intolerance of uncertainty (IU), and conspiracy beliefs in our two criterion variables (support for COVID-19 prevention measures and compliance with social distancing), we applied an online questionnaire to 662 participants. Our results indicate direct effects of political partisanship on support for COVID-19 prevention measures and non-compliance with social distancing while IU has not directly affected any of them. We have also found a significant effect of political partisanship on conspiracy theory dimensions involving personal wellbeing (PW) and control of information (CI) but not government malfeasance (GM) ones. Moreover, beliefs in CI theories predicted noncompliance with social distancing. Intolerance of uncertainty, on its turn, predicted the three dimensions of conspiracy beliefs. As to interaction effects, belief in GM, PW, and CI conspiracy theories moderated the effect of political partisanship on support for COVID-19 prevention measures whereas only belief in GM and PW theories moderated the effect of IU on past noncompliance with social distancing. Overall, our results suggest the relevance of diminishing politicization around the virus, providing basic scientific knowledge to the general population, and assisting individuals in coping with uncertainty. Besides, these findings provide insights into developing information campaigns to instruct the population to cope with the pandemic, producing behavioral change at societal and individual levels.
\end{abstract}

Keywords COVID-19 · Social distancing $\cdot$ Political partisanship · Conspiracy beliefs · Intolerance of uncertainty

Public Significance Statements

1) There is political polarization around the COVID-19 outbreak. This idea was supported by the results of this study, which indicate that rightwing partisans show less endorsement of COVID-19 prevention measures and comply with social distancing less often.

2) Conspiracy theories provide simple explanations to threatening societal events, diminishing feelings of uncertainty. Our findings suggest that people who believe in conspiracy theories involving control of information are more likely to breach social distancing guidelines.

3) High intolerance of uncertainty (IU) is related to choosing immediate and riskier rewards. In this research, individuals high on IU and holding stronger beliefs in government malfeasance and personal welfare conspiracy theories were found to be more prone to violate physical distancing.

Jessica Farias

jessicaemfarias@hotmail.com

1 Laboratory of Social Psychology, Institute of Psychology, Department of Social and Work Psychology, University of Brasilia, Brasilia, Brazil
The COVID-19 pandemic has become a topic of political polarization in some countries (Pennycook, McPhetres, Bago, \& Rand, 2020), causing political beliefs to present a significant limitation to the effectiveness of state-level social distancing orders (Painter \& Qiu, 2020). In the United States, political differences are the most consistent factor that distinguishes Americans health behaviors and policy preferences (Gadarian, Goodman, \& Pepinsky, 2020). For instance, Republicans are less likely to stay at home after a state order has been implemented in comparison with Democrats (Painter \& Qiu, 2020). While most Republicans tend to believe that the novel coronavirus has been made a bigger deal than it really is, just a small share of Democrats hold this sort of belief (Pew Research Center, 2020). Conservatives also dominate the discourse about COVID-19 conspiracy theories on Twitter (Havey, 2020) and tend to perceive less personal vulnerability to the virus as well as lower severity of the disease (Calvillo, Ross, Garcia, Smelter, \& Rutchick, 2020). 
Since the early stages of the COVID-19 pandemic, thousands of messages filled with conspiracy theories about "evil scientists" and "miracle cures" have continued to circulate on social media (Gadarian et al., 2020; Saxena, 2020). Such beliefs help individuals deal with anxiety, uncertainty, and feelings of lack of control (Van Prooijen \& Douglas, 2018), gaining momentum in the context of anxiety-provoking societal crisis events (Van Prooijen \& Douglas, 2017). Considering that the COVID-19 pandemic is a healththreatening major event that involves high uncertainty due to the fact that the disease is highly infectious and there is not either an effective medicine or vaccination against the virus so far, conspiracy theories (e.g. the virus is a bio-weapon released deliberately by China) thrive in an attempt to make sense of the pandemic.

This study aims at assessing the effect of political partisanship and IU on belief in conspiracy theories dimensions (government malfeasance - GM, personal welfare - PW, and control of information - CI). We also aim at examining whether political partisanship, IU, and these dimensions are significant predictors of support for COVID-19 measures and self-reported past compliance with social distancing. Our objective also lies in assessing the moderating role of belief in these dimensions in the effects of political partisanship and IU on both support for COVID-19 prevention measures and past compliance with social distancing.

\section{COVID-19, Political Partisanship, and Conspiracy Theories}

As the COVID-19 pandemic continues to spread, rumors about its emergence, possible treatments, and adequate prevention measures are rapidly circulating on social media and the news, some of which include conspiracy theories. A variety of conspiracy theories are tied to partisanship (Hartman \& Newmark, 2012; Pasek, Stark, Krosnick, \& Tompson, 2015; Smallpage, Enders, \& Uscinski, 2017), for partisans are prone to believe stories accusing opposing groups (Miller \& Saunders, 2016; Radnitz \& Underwood, 2015). Indeed, political partisanship is linked with belief in COVID-19 conspiracy theories (Alper, Bayrak, \& Yilmaz, 2020), having a significant effect on COVID-19 prevention measures (Farias \& Pilati, 2020; Pennycook et al., 2020), risk perceptions (Pennycook et al., 2020), and misperceptions (Pennycook et al., 2020).

The connection between belief in conspiracy theories and partisanship is attributed to partisan motivated reasoning (Miller \& Saunders, 2016), since belief in conspiracy theories involving opponents can lead individuals to view their own group as virtuous and adversary ones as nefarious (Claassen \& Ensley, 2016). Furthermore, conspiracy theories may consist of a relevant component of political identity. For instance, in the United States, the climate hoax is part of what it means to be a Republican whereas believing that the Iraq War was driven by oil companies is a significant component of the Democratic identity (Smallpage et al., 2017).

In American politics, examples of popular conspiracies are such as that President Kennedy was assassinated by an as-yetundiscovered group of conspirators, that the September 11 terrorist attacks were domestically orchestrated (Stempel, Hargrove, \& Stempel III, 2007), and that President Obama is Muslim (Hartman \& Newmark, 2012). In Brazil, left-wing supporters tend to endorse a conspiracy theory that the stabbing attack of then presidential candidate and now President Bolsonaro during his presidential campaign was staged (Paiva, 2019). On the other hand, Bolsonaro has suggested that the attacker did not act by himself (Avelar, 2019) and was politically motivated, even though investigators have already discarded this possibility, since the man was found to be mentally ill (NPR, 2019).

In the context of the COVID-19 pandemic, some conspiracy theories suggest that the $5 \mathrm{G}$ network activates the virus, that the pandemic is a hoax perpetrated by a global cabal, or that Bill Gates is using it as cover to launch a global surveillance regime (Shahsavari, Holur, Tangherlini, \& Roychowdhury, 2020). Other theories suggest that the Chinese Communist Party has intentionally manufactured the virus and the Deep State has produced the virus to ruin the economy and threaten President Trump's reelection chances (Havey, 2020). These theories all have in common the fact they provide simple explanations to the origin of the pandemic and make the current situation more comprehensible. Nevertheless, holding such beliefs may incur health risks, leading individuals to dismiss official guidance to prevent the spread of COVID-19 or to deliberately engage in risky behavior that spreads the virus (Pennycook et al., 2020). Considering the current political polarization around the virus, it is therefore conceivable to think that political partisanship be a significant predictor of both support for COVID-19 prevention measures and past compliance with social distancing.

Although there are numerous conspiracy theories, similar psychological processes drive people's belief in them (Van Prooijen \& Douglas, 2018). Indeed, the best predictor of belief in one conspiracy theory is belief in another conspiracy theory (Sutton \& Douglas, 2014; Swami et al., 2011). This endorsement holds true even for mutually incompatible conspiracy theories (Wood, Douglas, \& Sutton, 2012) and fictitious theories made up by psychological researchers (Swami et al., 2011).

Brotherton, French, and Pickering (2013) have developed a measure of individual differences in generic conspiracy belief. Despite the fact that this belief is considered a monological belief system unpinned by a relatively small number of generic assumptions, the authors have measured five dimensions of general conspiracy theories: governance malfeasance (GM), which comprises beliefs that the government is involved in 
secret major threatening events; extraterrestrial cover-up (ET), which involves beliefs that alien contact is being hidden; malevolent global conspiracies (MG), which encompasses beliefs that secret groups are responsible for world major decisions and events; personal wellbeing (PW), which comprises beliefs that secret technologies have being employed, and the spread of viruses/diseases has been taking place without people knowing about it; and control of information (CI), which comprehends beliefs in concealment of relevant evidence from the public. We expect these dimensions of conspiracy belief to be predictors support for COVID-19 prevention measures and past compliance with social distancing, especially GM, PW, and CI ones.

Conspiracy theories meet political extremists' desire to make sense of societal events through a series of unambiguous assumptions about the world (Van Prooijen, Krouwel, \& Pollet, 2015). Through compensatory conviction, uncertainty in one life domain is compensated with heightened certainty about one's ideologies such as opinions and values (McGregor, 2006), compensating for personal uncertainties by imbuing the world with meaning and purpose (Van Prooijen et al., 2015). Belief in simple political solutions facilitates dealing with feelings of uncertainty by making the world more understandable and predictable (Kruglanski, Pierro, Mannetti, \& De Grada, 2006). Political affiliations influence adherence to health behaviors (Gadarian et al., 2020), compliance with social distancing (Painter \& Qiu, 2020), and beliefs in the pandemic (Pew Research Center, 2020). We therefore expect that belief in conspiracy theories moderate the effect of political partisanship on endorsement of COVID-19 prevention measures and compliance with social distancing.

Uncertainty has the potential to increase conspiracy beliefs (Newheiser, Farias, \& Tausch, 2011; Van Prooijen \& Jostmann, 2013). Individuals who are intolerant of uncertainty may benefit from belief in conspiracy theories because they provide straightforward and structured answers for difficult questions (Marchlewska, Cichocka, \& Kossowska, 2018). On its turn, IU bias decision making towards shorter wait times and more frequent selection of the immediate and riskier rewards, being associated with an aversion to waiting in a state of uncertainty (Luhmann, Ishida, \& Hajcak, 2011). Besides, uncertainty avoidance has been associated with a higher level of belief in COVID-19 conspiracy theories (Alper et al., 2020). Therefore, we expect that highly intolerant of uncertainty individuals be more prone to believe general conspiracy theories, show less endorsement of COVID-19 prevention measures, and violate social distancing more often.

\section{Method}

\section{Participants}

Participants were obtained through convenience sampling. A total of 662 participants answered an online questionnaire. There were 495 women, 163 men, and four participants did not report gender. The mean age was 39.91 ( $\mathrm{SD}=14.15$ ), ranging from 18 to 82 years. Most participants stated to be leftwing supporters $(n=360,54.4 \%), 221$ declared not to be either right- or left wing-partisans $(36.7 \%)$, and 81 stated to be rightwing supporters $(12.2 \%)$. The distribution across political divides is uneven, more skewed towards left-wing supporters because participants have been recruited throw chain-referral sampling by using WhatsApp - a popular messaging app in Brazil - as well as Facebook. For this reason, we have not been able to control the number of participants according to their political ideology. The most cited income bracket was from four to ten minimal wages $(25.8 \%)$. Our sample is highly educated, seeing that $400(60.4 \%)$ participants checked the graduate option, meaning they are either postgraduate students or have already finished a postgraduate degree. Another $23.4 \%$ have completed an undergraduate course and $13.1 \%$ are undergraduate students. Only $3.7 \%$ of the sample did not hold an undergraduate degree. Participants were from all five geopolitical Brazilian regions (North, Northeast, Center west, Southeast, and South). Most of them were concentrated in the Federal District and in the State of São Paulo (52.1\% and $11.2 \%$, respectively).

\section{Measures}

Compliance with Social Distancing One item asking about the frequency participants left their homes during the COVID-19 pandemic. It was scored at 5 points $(1=$ Never, $2=\mathrm{A}$ few times, $3=$ Once in a while, $4=$ Many times, $5=$ Whenever I wanted to).

Measures to Combat COVID-19 Five items on measures to combat the spread of COVID-19. Participants stated to what extent they agreed with the measures' applicability on a scale scored at five points ( 1 = Strongly disagree, $2=$ Partially disagree, 3 = Neither agree nor disagree, $4=$ Partially agree, and $5=$ Strongly agree). The measures evaluated were: (1) horizontal social distancing, (2) vertical social distancing (defending only the isolation of at-risk groups), (3) closure of commercial venues, (4) issuance of fines to individuals who violate social distancing, and (5) incarceration. The Cronbach's $\alpha$ coefficient of the scale was .71.

IUS-12 (Intolerance of Uncertainty Scale, Short Version) The short version of the IUS-12 (Intolerance of Uncertainty Scale) adapted by Carleton, Norton, and Asmundson (2007) was used. The scale is comprised of 12 items which are grouped in two dimensions (prospective anxiety and inhibitory anxiety). A 5-point scoring was adopted ( $1=$ Strongly disagree, $2=$ Partially disagree, $3=$ Neither agree nor disagree, $4=$ Partially agree, and $5=$ Strongly agree). The higher the score was, the higher was participants' intolerance of uncertainty level. The Cronbach's $\alpha$ coefficient of the scale was .91. The ones of prospective anxiety and inhibitory anxiety were both .85 . The 
results of a confirmatory factor analysis showed that the construct validity was good: $\mathrm{CFI}=.97, \mathrm{RMSEA}=.06, \mathrm{SRMR}=$ .04 (Carleton et al., 2007).

Conspiracy Beliefs Scale (Short-Form) The scale was elaborated by Brotherton et al. (2013), consisting of 15 items intended to reflect generic conspiracy beliefs. Each item refers to a generic belief which could support belief in various real-world conspiracy theories. Participants rated items on a 5-point Likert-type scale, with a qualitative label associated with each point (1= Definitely not true, $2=$ Probably not true, $3=$ Cannot decide, $4=$ Probably true, and $5=$ Definitely true). The scale has five dimensions: Government Malfeasance, Malevolent Global Conspiracies, Extraterrestrial Cover-up, Personal Wellbeing, and Control of Information. The scale's internal reliability was extremely high $(\alpha=.95)$ (Brotherton et al., 2013). A confirmatory factor analysis indicated that the 5-dimension model has a good fit: $\chi 2=140.76\left(\mathrm{df}=80, p<0.001, \chi^{2} / \mathrm{df}=1.76\right), \mathrm{CFI}=0.97$, GFI $=0.92$, RMSEA $=0.06$, and RMR $=0.06$ (Brotherton et al., 2013). In this study, however, we are particularly interested in the dimensions of Government Malfeasance, Personal Wellbeing, and Control of Information. Government Malfeasance and Control of Information are factors of interest because we are investigating the role of political ideologies, and Personal Wellbeing is relevant because the research context involves a health crisis. In this research, their Cronbach $\alpha$ 's were $.93, .87$, and .78 , respectively.

Political Partisanship One question scored at 8 points $(1=$ Far right wing, $2=$ Regular right wing, $3=$ Moderate right wing, $4=$ Neither right or left wing, $5=$ Moderate left wing, $6=$ Regular left wing, and $7=$ Far left wing).

\section{Procedure}

The questionnaire was applied online during the pandemic, from April to May 2020. Participants were invited to respond to the research through Facebook posts, and invitations were sent through a messaging app - WhatsApp — to the researchers' contacts. In the invitation, there was a request to send the questionnaire to other contacts or groups. Participants were introduced the purpose of the study and then asked to sign informed consent, which stated that the survey was conducted anonymously, that the results were intended for academic research only, and that all information would be kept confidential. To answer the study, they must have been 18 years old or above. The collected data were sorted and analyzed by SPSS 22.0. Moderation analyses were performed by using the PROCESS macro for SPSS version 3.5 (Hayes, 2013).

This study strictly followed the Ethical Principles in the Conduct of Research with Human Participants proposed by the American Psychological Association. Participants were informed about the research purposes, the risks involved in taking part of it, and the confidentiality and anonymity of the participation. Participants explicitly informed their consent in taking part in the research by checking a box and were free to quit their participation at any moment. No personal information was collected to preserve participants' anonymity.

\section{Results}

To assess the effect of political partisanship on belief in conspiracy theories, regression analyses were performed. We found that political partisanship did not significantly predict belief in GM theories, $\mathrm{F}(659,1)=2.83, \mathrm{t}(662)=1.68, \mathrm{~b}=.047, p=.09, \mathrm{R}^{2}=$ $.004,95 \%$ CI $[-.008, .102]$. Nevertheless, it was a significant predictor of both PW theories, $\mathrm{F}(659,1)=6.41, \mathrm{t}(662)=$ $-2.53, \mathrm{~b}=-.078, p=.01, \mathrm{R}^{2}=.010,95 \%$ CI $[-.139,-.118]$ and $\mathrm{CI}$ theories, $\mathrm{F}(659,1)=6.60, \mathrm{t}(662)=-2.57, \mathrm{~b}=-.07$, $\mathrm{p}=.01, \mathrm{R}^{2}=.01,95 \% \mathrm{CI}[-.123,-.016]$. Other three regression analyses have been performed to assess the effect of IU on dimensions of belief in conspiracy theories. IU significantly predicted GM theories, $\mathrm{F}(659,1)=151.94, \mathrm{t}(662)=12.33, \mathrm{~b}=.43$, $p<.001, \mathrm{R}^{2}=.19,95 \% \mathrm{CI}[0.58, .79]$, PW theories, $\mathrm{F}(660,1)=$ $283.35, \mathrm{t}(662)=16.83, \mathrm{~b}=.55, \mathrm{p}<.001, \mathrm{R}^{2}=.30,95 \% \mathrm{CI}[.85$, 1.07], and $\mathrm{CI}$ theories, $\mathrm{F}(660,1)=312.42, \mathrm{t}(662)=312.41, \mathrm{~b}=$ $17.67, \mathrm{p}<.001, \mathrm{R}^{2}=.32,95 \%$ CI $[.77, .97]$.

Additional multiple regression analyses were carried out to evaluate the impact of political partisanship, IU, and the dimensions of belief in conspiracy theories (GM, PW, and CI) on both support for COVID-19 prevention measures and on past non-compliance with social distancing. Endorsement of prevention measures was calculated by computing the mean score of the five items concerning COVID-19 prevention measures (horizontal interdiction, vertical interdiction, closing of commercial venues, incarceration, and issuance of fines). We found that political partisanship was a significant predictor of support for prevention measures and past lack of compliance with social distancing. IU in turn did not significantly predict either endorsement of COVID-19 prevention measures or non-compliance with social distancing. Additionally, belief in GM and PW theories did not significantly predict support for COVID-19 prevention measures as well as compliance with social distancing. Belief in CI theories, however, significantly affected lack of compliance with social distancing but not support for prevention measures (check Table 1 for further information).

Belief in GM, PW, and CI conspiracy theories significantly moderated the effect of political partisanship on support for COVID-19 prevention measures. However, they did not significantly moderate the effect on non-compliance with social distancing. Moreover, only beliefs in GM and CI theories moderated the effect of IU on past non-compliance with social distancing. None of them moderated the effect of IU on 
support for COVID-19 prevention measures (see Tables 2 and 3 for better visualization of moderation analyses).

To describe the significant moderating effects more accurately, we have plotted graphs in which it is possible to observe the interactions among the variables (Figs. 1, 2, 3, 4, 5 and 6). To plot the graphs, we have automatically divided political partisanship into three categories by using the PROCESS package $(4=$ right-wing and center, $6=$ moderate left-wing, and $8=$ far left-wing).

\section{Discussion}

In this study, we aimed at finding evidence of the direct effects of political partisanship and IU on conspiracy beliefs. We also intended to assess the direct effects of three variables (political partisanship, IU, and dimensions of belief in conspiracy theories) on endorsement of COVID-19 prevention measures as well as on past compliance with social distancing. Additionally, this research has contributed to shedding light on the moderating role of conspiracy beliefs in the effect of political partisanship and IU on endorsement of prevention measures and compliance with social distancing.

Significant effects of political partisanship on belief in PW and CI theories have been found. This result is in line with the findings reported by Hartman and Newmark (2012), Pasek et al. (2015), and Smallpage et al. (2017), and can be explained by the tendency that partisans have to believe conspiracy theories that involve opposing groups (Miller \& Saunders, 2016; Radnitz \& Underwood, 2015). Furthermore, we found that political partisanship significantly predicted support for COVID-19 prevention measures and compliance with social distancing, indicating that left-wing partisans are more prone to show stronger endorsement of these measures and are more likely to comply with physical distancing. This finding is consistent with reports that political differences have an impact on health behaviors and policy preferences (Gadarian et al., 2020; Havey, 2020; Painter \& Qiu, 2020; Pew Research Center, 2020).

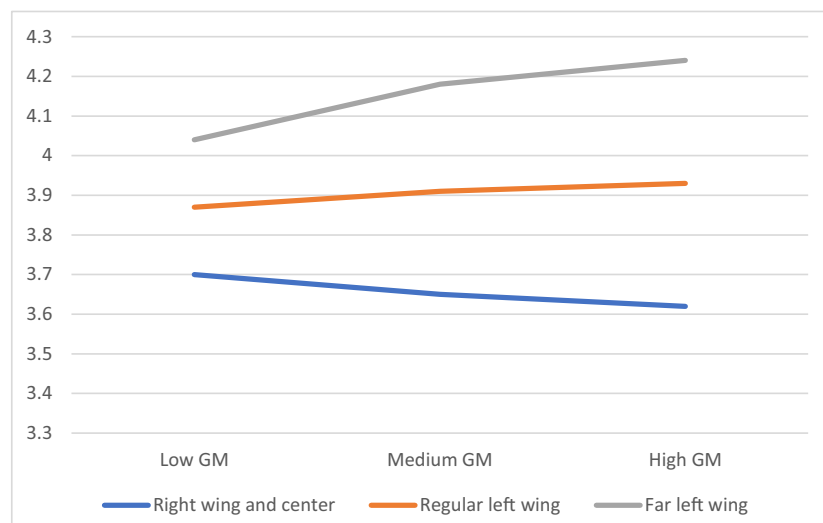

Fig. 1 Impact of Political Partisanship on Support for Prevention Measures under the Influence of Belief in GM theories

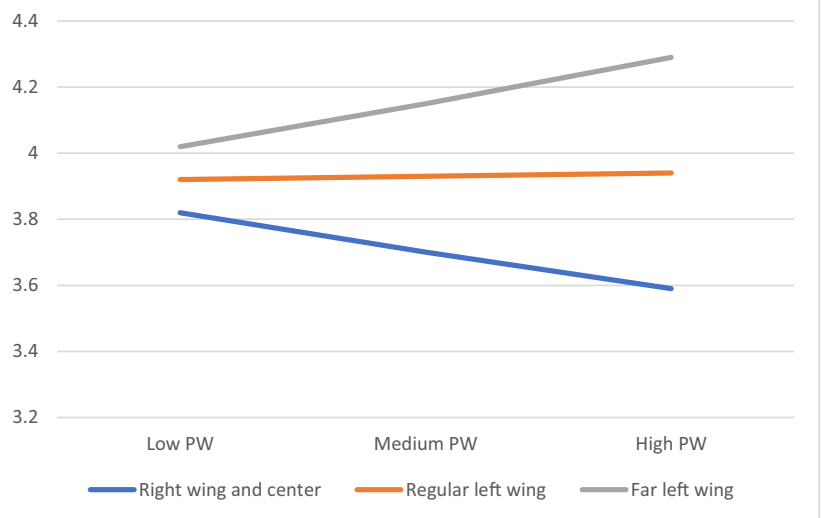

Fig. 2 Impact of Political Partisanship on Support for Prevention Measures under the Influence of Belief in PW theories

On the other hand, IU significantly predicted the three dimensions of conspiracy theories, accounting for a substantial proportion of their variance. This result provides support for the reports of Newheiser et al. (2011) as well as Van Prooijen and Jostmann (2013), stating that intolerance of uncertainty may increase belief in conspiracy theories because they provide simple and structured answers for burdensome questions (Marchlewska et al., 2018). Despite being a significant sole predictor of conspiracy theories, there are no direct effects of IU on either support for COVID-19 prevention measures or social-distancing violation. Even though highly uncertaintyintolerant individuals did not leave their houses more often than the ones with low IU in the present research, they expressed weaker intentions of compliance with social distancing during the COVID-19 pandemic in another study (Farias \& Pilati, 2020). The gap that exists between attitudes, intentions, and actual behaviors (Sheeran \& Webb, 2016) may explain these opposing results. Farias and Pilati (2020) have measured intentions of complying with social distancing while, in this study, the criterion variables are support for COVID-19 prevention measures (attitudes) and compliance with social distancing (self-reported past behavior).

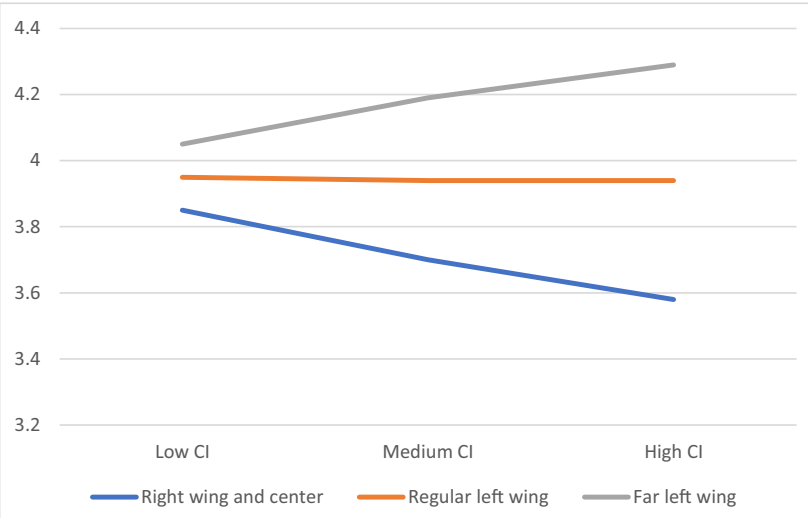

Fig. 3 Impact of Political Partisanship on Support for Prevention Measures under the Influence of Belief in CI theories 


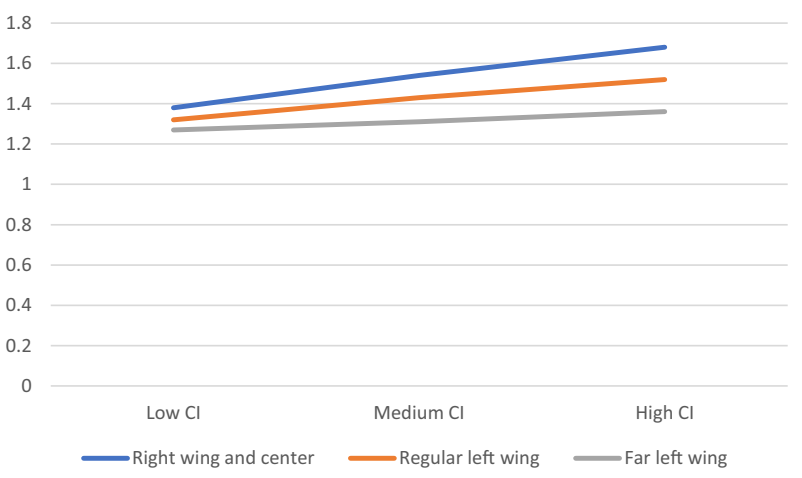

Fig. 4 Impact of Political Partisanship on Non-compliance with Social Distancing under the Influence of Belief in CI theories

Additionally, we evaluated the moderating effect of belief in conspiracy theories on the effects of political partisanship and IU on support for prevention measures and compliance with social distancing. Beliefs in GM, PW, and CI conspiracies moderated the effect of political partisanship on endorsement of COVID-19 prevention measures. In fact, the stronger the belief in GM theories among far and moderate left-wing supporters, the more support for prevention measures. On the other hand, when it comes to right-wing and center partisans, the stronger the beliefs, the weaker the endorsement of prevention measures. Considering that GM theories involve conceiving that the government may be engaged in threatening events, non-supporters of the current government - which is right wing - may be more inclined to believe in this type of conspiracies. This result is, therefore, in line with political motivated reasoning (Miller \& Saunders, 2016).

As to the moderation of $\mathrm{PW}$ and $\mathrm{CI}$ conspiracies on the effect of political affiliation on COVID-19 prevention measures, a similar trend has been found. That is, the stronger these beliefs are among far and moderate left-wing partisans, the stronger the support for preventive measures while the opposite holds true for center and right-wing partisans. It means that conspiracy theories have a more detrimental effect on center and right-wing partisans if compared to left-wing

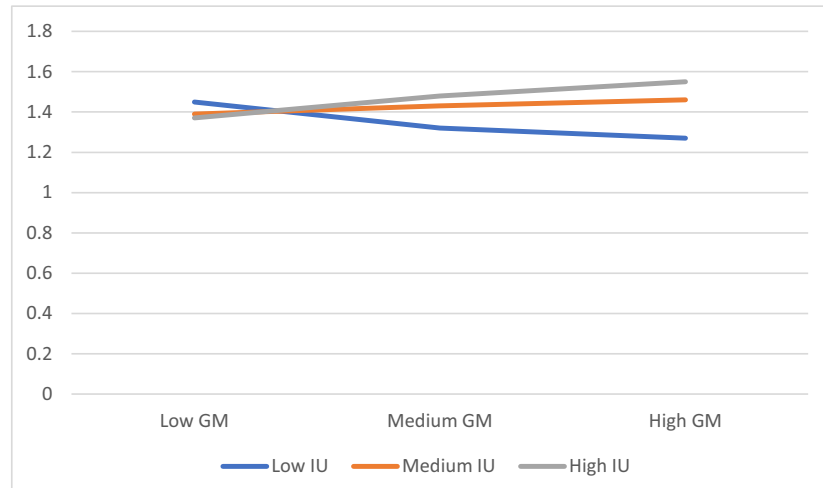

Fig. 5 Impact of Intolerance of Uncertainty on Non-compliance with Social Distancing under the Influence of Belief in GM theories

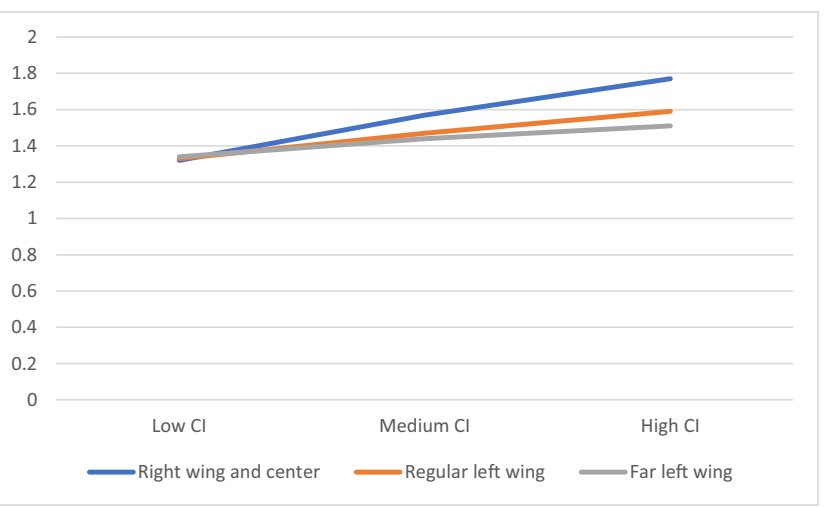

Fig. 6 Impact of Intolerance of Uncertainty on Non-compliance with Social Distancing under the Influence of Belief in CI theories

ones. Our results indicate that conspiracy theories affect support for COVID-19 preventive measures among people of divergent political affiliations differently and that conspiracy theories consist of a factor that exacerbates political polarization around the virus. When it comes to the impact on lack of compliance with social distancing, belief in CI theories was the only significant moderator of the effect of political partisanship. Non-compliance with social distancing increased across all three groups of partisans as belief in CI theories rose. These results suggest that belief in conspiracy theories may potentiate politicization around the COVID-19 pandemic, increasing negative attitudes toward prevention measures.

There have been significant indirect effects of IU on socialdistancing violation. Specifically, belief in GM and CI theories moderated the effect of IU on social-distancing violation. Individuals who are high and medium on IU and hold stronger beliefs in GM theories tend to violate social distancing more often whereas the ones who hold any level of IU - either low, medium, or high - are more prone not to comply with social distancing as belief in CI theories becomes stronger. These results support the reports that there is a link between uncertainty and conspiracy beliefs (Newheiser et al., 2011; Van Prooijen \& Jostmann, 2013). Since conspiracies provide simple and structured answers for burdensome questions (Marchlewska et al., 2018), individuals who are high on IU may benefit from such beliefs. Nevertheless, this association may be hazardous because decision makers who score high on IU may consider long periods of uncertainty to be aversive and make quicker and riskier decisions in an attempt to avoid unpleasant emotions (Luhmann et al., 2011). In the context of the pandemic, highly uncertainty-intolerant individuals who believe in conspiracy theories are more prone to make the riskier decision of violating the most efficient strategy to curb the rapid spread of the COVID-19 disease.

This study has some limitations. First, previous research has shown that political cynicism and distrust in institutions typically increase in times of economic crises and are frequently associated with the better electoral performance of extremist parties (Rydgren, 2005). In Brazil, right-wing 
supporters are characterized by conservatism in habits and liberalism in economic affairs while the opposite holds true for left-wing partisans. Therefore, a more effective way of measuring political ideologies in Brazil could be applying separate measures to assess participants' position on economy and consuetude. Second, considering the sample recruitment strategy, our final sample was uneven in terms of political orientation, which may have biased the results. Further research should develop strategies to balance such sample features, seeking to evaluate whether the patterns of results we found remains the same.

Third, we have not measured belief in COVID-19 conspiracy theories but only general belief in conspiracies. We applied a general measure, relying on the concept that belief in conspiracy theories consists of a monological belief system underlain by a small number of generic assumptions (Van Prooijen \& Douglas, 2017). We also considered the reports by previous research (Sutton \& Douglas, 2014; Swami et al., 2011) that indicated that the best predictor of belief in one conspiracy theory is belief in another one. Nevertheless, we suggest that future research investigate the effect of specific conspiracy theories on endorsement of and compliance with COVID-19 prevention measures.

Fourth, further research regarding the COVID-19 pandemic may apply novel measures that have been developed during the period of intense scientific production of the past months, such as the one conducted by Abdelrahman (2020). When we designed the data collection, only a few measures to evaluate relevant behavioral variables to cope with the pandemic had been made available in the scientific literature, none in Brazilian Portuguese. Finally, since Brazil's president is far-right wing and shows constant disregard for science (Philips \& Briso, 2020; Tollefson, 2020) - which could in turn influence right-wing partisans toward endorsing such point of view - we urge future research to delve into the impact of distrust of science on holding conspiracy beliefs as well as on attitudes, intentions and behaviors regarding COVID-19 prevention measures.

This study has brought twofold contributions. From a theoretical perspective, its contribution lies in providing further evidence to the effect of political partisanship, beliefs in conspiracy theories and IU on the COVID-19 pandemic endorsement of prevention measures as well as on lack of compliance with the most effective measure to prevent the pandemic from rapidly spreading - social distancing. Previous research had indicated that political partisanship and IU are predictors of intentions of complying with social distancing (Farias \& Pilati, 2020). We have then sought to deepen the knowledge on this subject, investigating whether conspiracy beliefs moderated the effect of these two variables on both prevention measures and actual compliance. Understanding the role of variables that underlie belief in false information in the context of the COVID-19 pandemic is crucial, since rumors may lead individuals to believe incorrect information about prevention measures, incurring health risks and jeopardizing prevention strategies that depend on social cooperation. A variety of studies has shown that people hold anti-science beliefs largely because they do not possess enough basic scientific knowledge to properly understand science-related claims (Allum, Sturgis, Tabourazi, \& Brunton-Smith, 2008; Sturgis \& Allum, 2004). Therefore, the need to provide accessible scientific information becomes pivotal in the fight against misinformation and its consequences as to adherence to COVID-19 preventive measures.

Psychological science produces insights that can assist in coping with pandemics, ranging from developing public policies to helping individuals in the clinical setting (Taylor, 2019). From a practical point of view, psychologists may consider the results of our research to design public policies aimed at providing individuals with basic scientific knowledge, assisting people in recognizing reliable sources of information to prevent belief in fake data or misinformation. Since the current threat faced in the context of the pandemic is a virus, supplying the general population with access to fundamental biological knowledge in a simple and clear manner may be the most effective tool to prevent misinformation and consequent health-risk behavior. Psychologists can also help governmental public health organizations to develop microtargeting procedures based on conspiracy beliefs mapped in this research as a strategy to provide specific and effective reliable information, seeking to foster positive attitudes toward preventive measures. Such kind of microtargeting strategies have the potential to curb the effects of conspiracy beliefs on individual's behavior.

In addition, our results may help psychologists with individual counseling through the development of strategies aimed at increasing the adhesion of individuals to sanitary behavioral measures. These strategies should focus on information and orientation in the clinical setting, providing resources to produce immunization against conspiracy beliefs persuasion. Another possibility brought by our results - also applicable to psychologists working in the clinical setting consists of working on developing psychological support intended for aiding individuals in dealing with uncertainty, since IU is a factor that indirectly affects compliance with social distancing.

Overall, we have found further evidence which supports that political partisanship jeopardizes endorsement of COVID-19 prevention measures. Considering that partisan identification slants decision-making (Bolsen, Druckman, \& Cook, 2014) due to partisan motivated reasoning (Miller \& Saunders, 2016) and causes citizens to support policies that they would otherwise oppose in the absence of an endorsement from a political party (Miller \& Saunders, 2016), it is crucial that politicians who hold different political ideologies show endorsement of prevention measures. The results of our research have provided empirical evidence that politization 
around COVID-19 endangers the effectiveness of public strategies to cope with the pandemic. Thus, it is of uttermost importance that health strategies toward coping with pandemics do not be politicized. Moreover, working towards educating the general population in basic scientific and biological knowledge concerning the disease may diminish the adoption of health risk behaviors among highly uncertainty-intolerant individuals. We hope that our results can be insightful to prevent political polarization and misinformation in pandemics that the global population may face in the future.

Availability of Data and Material The datasets for this study can be found in the OSF platform on this link https://osf.io/mpyt4/.

Authors' Contributions The first and second authors contributed to the conception and design of the study. Both authors collected the raw data, and the first author organized the database. The first author performed statistical analyses and wrote the first draft of the manuscript. The second author revised it critically for important intellectual content.

Funding The present work received support from CAPES (Coordination for the Improvement of Higher Education Personnel), in the form of a $\mathrm{PhD}$ scholarship (88887.511193/2020-00) for the first author, as well as from $\mathrm{CNPq}$ (National Council for Scientific and Technological Development), in the form of a Research Productivity Grant (302414/ 2019-3) for the second author.

Code Availability Not applicable.

\section{Compliance with Ethical Standards}

Conflict of Interest The authors declare that the research was conducted in the absence of any commercial or financial relationships that could be construed as a potential conflict of interest.

We have no known conflict of interest to disclose.

Ethics Approval This study strictly followed the Ethical Principles in the Conduct of Research with Human Participants proposed by the American Psychological Association. Participants were informed about the research purposes, the risks involved in taking part of the research as well as the confidentiality and anonymity of the participation. The research protocol was not submitted to an approving institutional review board because the committee's rules and regulations in Brazil only evaluate projects in the realm of medical and pharmacological research. Considering this situation regarding the current national regulations, it is not required to obtain approval from an institutional review board to conduct studies with human subjects in social and behavioral sciences.

Consent to Participate Participants explicitly informed their consent in taking part in the research by checking a box and were free to quit participation at any moment. No personal information was collected to preserve participants' anonymity.

Consent for Publication All data collected were unidentified and analyzed in a grouped manner so that each participant who answered the research is anonymous. Informed consent on the academic purpose of the data collection was obtained from all individual participants.

\section{Appendix 1}

Table 1 Summary of multiple regression analyses and bivariate correlations for support to COVID-19 prevention measures (Meas) and past non-compliance with social distancing (Com) as criterion variables and with political partisanship, intolerance of uncertainty, belief in government malfeasance (GM), personal welfare (PW), and control of information $(\mathrm{CI})$ theories as antecedents $(N=662)$

\begin{tabular}{|c|c|c|c|c|c|c|c|c|c|}
\hline & & & & & & & & $\begin{array}{l}\text { Model I } \\
\text { Meas }\end{array}$ & $\begin{array}{l}\text { Model II } \\
\text { Com }\end{array}$ \\
\hline Variables & Pol & IUS & GM & PW & $\mathrm{CI}$ & Meas & Com & $\begin{array}{l}\beta \\
{[\mathrm{B} 95 \% \mathrm{CI}]}\end{array}$ & $\begin{array}{l}\beta \\
{[\mathrm{B} 95 \% \mathrm{CI}]}\end{array}$ \\
\hline Pol & - & & & & & & & $\begin{array}{l}.44+ \\
{[.20, .29]}\end{array}$ & $\begin{array}{l}-.27+ \\
{[-.15,-.08]}\end{array}$ \\
\hline IUS & .03 & - & & & & & & $\begin{array}{l}.08 \\
{[-.01, .16]}\end{array}$ & $\begin{array}{l}-.02 \\
{[-.09, .05]}\end{array}$ \\
\hline GM & $.26+$ & $.43+$ & - & & & & & $\begin{array}{l}-.03 \\
{[-.07, .04]}\end{array}$ & $\begin{array}{l}.03 \\
{[-.03, .06]}\end{array}$ \\
\hline PW & -.04 & $.55+$ & $.52+$ & - & & & & $\begin{array}{l}.01 \\
{[-.06, .07]}\end{array}$ & $\begin{array}{l}-.04 \\
{[-.07, .04]}\end{array}$ \\
\hline $\mathrm{CI}$ & $-.12^{*}$ & $.57+$ & $.40+$ & $.78+$ & - & & & $\begin{array}{l}-.05 \\
{[-.10, .04]}\end{array}$ & $\begin{array}{l}.17^{*} \\
{[.02, .14]}\end{array}$ \\
\hline Meas & $.44+$ & .05 & $.10+$ & -.02 & -.07 & - & & & \\
\hline Com & $-.28+$ & .06 & -.006 & $.10+$ & $.17+$ & $-.47+$ & - & & \\
\hline Mean & 4.83 & 3.57 & 3.62 & 3.09 & 3.12 & 3.88 & 2.26 & & \\
\hline SD & 1.37 & .82 & 1.29 & 1.43 & 1.25 & .77 & .76 & & \\
\hline
\end{tabular}


Table 1 (continued)

\begin{tabular}{|c|c|c|c|c|c|c|c|c|c|}
\hline \multirow[b]{2}{*}{ Variables } & \multirow[b]{2}{*}{ Pol } & \multirow[b]{2}{*}{ IUS } & \multirow[b]{2}{*}{ GM } & \multirow[b]{2}{*}{ PW } & \multirow[b]{2}{*}{$\mathrm{CI}$} & \multirow[b]{2}{*}{ Meas } & \multirow[b]{2}{*}{ Com } & \multirow{2}{*}{$\begin{array}{l}\text { Model I } \\
\text { Meas } \\
\beta \\
{[\mathrm{B} 95 \% \mathrm{CI}]}\end{array}$} & \multirow{2}{*}{$\begin{array}{l}\text { Model II } \\
\text { Com } \\
\beta \\
{[\mathrm{B} 95 \% \mathrm{CI}]}\end{array}$} \\
\hline & & & & & & & & & \\
\hline $\mathrm{R}^{2}$ & & & & & & & & .20 & .10 \\
\hline Adj $R^{2}$ & & & & & & & & .19 & .09 \\
\hline $\mathrm{F}$ & & & & & & & & 32.50 & 14.24 \\
\hline
\end{tabular}

$+p<.001, * p<.05$

Pol = Political Partisanship; IU = Intolerance of Uncertainty; GM = Belief in Government Malfeasance Theories; PW = Belief in Personal Welfare Theories; CI = Belief in Control of Information Theories; Meas = Endorsement of COVID-19 Prevention Measures; Comp = Non-compliance with Social Distancing

\section{Appendix 2}

Table 2 Summary of analyses of GM, PW, and CI theories as moderating variables of the effect of political partisanship on support to COVID-19 prevention measures and past non-compliance with social distancing $(\mathrm{N}=662)$

\begin{tabular}{lllllll}
\hline Variables & $\mathrm{t}$ & $\mathrm{B}$ & $95 \% \mathrm{CI}$ & $\mathrm{F}$ & $\mathrm{R}^{2}$ & Adjusted $^{2}$ \\
\hline
\end{tabular}

Endorsement of COVID-19 Prevention Measures

$\begin{array}{lllllll}\mathrm{GM} & 3.26+ & .05 & {[.02, .07]} & 57.26+ & .45 & .20 \\ \mathrm{PW} & 5.64+ & .07 & {[.05, .10]} & 65.47+ & .48 & .23 \\ \mathrm{CI} & 5.24+ & .08 & {[.05, .11]} & 66.75+ & .47 & .22\end{array}$

Non-compliance with Social Distancing

\begin{tabular}{lllllll} 
GM & .95 & .01 & {$[-.01, .03]$} & $20.22+$ & .29 & .08 \\
PW & -1.75 & -.02 & {$[-.04, .002]$} & $21.77+$ & .30 & .09 \\
CI & $-2.53 *$ & -.03 & {$[-.06,-.007]$} & $25.64+$ & .32 & .10 \\
\hline
\end{tabular}

$+\mathrm{p}<.001, * \mathrm{p}<.05$

$\mathrm{GM}=$ Belief in Government Malfeasance Theories; $\mathrm{PW}=$ Belief in Personal Welfare Theories; CI $=$ Belief in Control of Information Theories

\section{Appendix 3}

Table 3 Summary of analyses of GM, PW and CI theories as moderating variables of the effect of intolerance of uncertainty on support to COVID-19 prevention measures (Meas) and past noncompliance with social distancing $(\mathrm{Com})(\mathrm{N}=662)$

\begin{tabular}{lllllll}
\hline Variables & $\mathrm{t}$ & $\beta$ & $95 \% \mathrm{CI}$ & $\mathrm{F}$ & $\mathrm{R}^{2}$ & Adjusted $\mathrm{R}^{2}$ \\
\hline \multicolumn{7}{l}{ Non-compliance with Social Distancing } \\
$\mathrm{GM}$ & -1.58 & -.04 & {$[-.10, .01]$} & $3.22^{*}$ & .12 & .01 \\
$\mathrm{PW}$ & 1.62 & .05 & {$[-.01, .11]$} & 2.34 & .10 & .01 \\
$\mathrm{CI}$ & 1.67 & .05 & {$[-.009, .12]$} & 4.78 & .15 & .02 \\
Non-compliance with Social Distancing & & & \\
$\mathrm{GM}$ & $3.25^{*}$ & .07 & {$[.03, .11]$} & $4.46^{*}$ & .14 & .02 \\
$\mathrm{PW}$ & .13 & .003 & {$[-.04, .05]$} & 2.33 & .10 & .01 \\
$\mathrm{CI}$ & $-2.11^{*}$ & -.05 & {$[-.10,-.004]$} & $8.50+$ & .19 & .04 \\
\hline
\end{tabular}

$+\mathrm{p}<.001, * \mathrm{p}<.05$

$\mathrm{GM}=$ Belief in Government Malfeasance Theories; PW = Belief in Personal Welfare Theories; CI $=$ Belief in Control of Information Theories; Measures = Endorsement of COVID-19 Prevention Measures; Non-compliance $=$ Non-compliance with Social Distancing 


\section{References}

Abdelrahman, M. K. (2020). Personality traits, risk perception, and protective behaviors of Arab residents of Qatar during the COVID-19 pandemic. PsyArXiv. https://doi.org/10.1007/s11469-020-00352-7.

Allum, N., Sturgis, P., Tabourazi, D., \& Brunton-Smith, I. (2008). Science knowledge and attitudes across cultures: A meta-analysis. Public Understanding of Science, 17(1), 35-54. https://doi.org/10. 1177/0963662506070159.

Alper, S., Bayrak, F., \& Yilmaz, O. (2020). Psychological correlates of COVID-19 conspiracy beliefs and preventive measures: Evidence from Turkey. Current Psychology. https://doi.org/10.1007/s12144020-00903-0.

Avelar, D. (2019). The Guardian. WhatsApp fake news during Brazil election 'favoured Bolsonaro'. https:/www.theguardian.com/ world/2019/oct/30/whatsapp-fake-news-brazil-election-favouredjair-bolsonaro-analysis-suggests.

Bolsen, T., Druckman, J. N., \& Cook, F. L. (2014). The influence of partisan motivated reasoning on public opinion. Political Behavior, 36, 235-262. https://doi.org/10.1007/s11109-013-92380 .

Brotherton, R., French, C. C., \& Pickering, A. D. (2013). Measuring belief in conspiracy theories: The generic conspiracy beliefs scale. Frontiers in Psychology, 4, 279. https://doi.org/10.3389/fpsyg. 2013.00279.

Calvillo, D. P., Ross, B. J., Garcia, R. J. B., Smelter, T. J., \& Rutchick, A. M. (2020). Political ideology predicts perceptions of the threat of COVID-19 (and susceptibility to fake news about it). Social Psychological and Personality Science, 11(8), 1119-1128. https:// doi.org/10.1177/1948550620940539.

Carleton, R. N., Norton, M. A. P. J., \& Asmundson, G. J. G. (2007). Fearing the unknown: A short version of the intolerance of uncertainty scale. Journal of Anxiety Disorders, 21(1), 105-117. https:// doi.org/10.1016/j.janxdis.2006.03.014.

Claassen, R. L., \& Ensley, M. J. (2016). Motivated reasoning and yardsign-stealing partisans: Mine is a likable rogue, yours is a degenerate criminal. Political Behavior, 38(2), 317-335. https://doi.org/10. 1007/s11109-015-9313-9.

Farias, J., \& Pilati, R. (2020). Violating social distancing amid the COVID-19 pandemic: Psychological factors to improve compliance. PsyArXiv Preprints [Preprint].https://doi.org/10.31234/osf. io/apg9e.

Gadarian, S, K., Goodman, S, W., \& Pepinsky, T, B. (2020). Partisanship, health behavior, and policy attitudes in the early stages of the COVID-19 pandemic. SSRN. https://ssrn.com/abstract= 3562796 or https://doi.org/10.2139/ssrn.3562796.

Hartman, T. K., \& Newmark, A. J. (2012). Motivated reasoning, political sophistication, and associations between President Obama and Islam. PS: Political Science and Politics, 45(03), 449-455.

Havey, N. F. (2020). Partisan public health: How does political ideology influence support for COVID-19 related misinformation? Journal of Computational Social Science, 3, 319-342. https://doi.org/10.1007/ s42001-020-00089-2.

Hayes, A. F. (2013). Introduction to mediation, moderation, and conditional process analysis: A regression-based approach. New York, NY: The Guilford Press.

Kruglanski, A. W., Pierro, A., Mannetti, L., \& De Grada, E. (2006). Groups as epistemic providers: Need for closure and the unfolding of group-centrism. Psychological Review, 113(1), 84-100. https:// doi.org/10.1037/0033-295X.113.1.84.

Luhmann, C. C., Ishida, K., \& Hajcak, G. (2011). Intolerance of uncertainty and decisions about delayed, probabilistic rewards. Behavior Therapy, 42(3), 378-386. https://doi.org/10.1016/j.beth.2010.09. 002 .
Marchlewska, M., Cichocka, A., \& Kossowska, M. (2018). Addicted to answers: Need for cognitive closure and the endorsement of conspiracy beliefs. European Journal of Social Psychology, 48, 109117. https://doi.org/10.1002/ejsp.2308.

McGregor, I. (2006). Offensive defensiveness: Toward an integrative neuroscience of compensatory zeal after mortality salience, personal uncertainty, and other poignant self-threats. Psychological Inquiry, 17, 299-308. https://doi.org/10.1080/10478400701366977.

Miller, J. M., \& Saunders, K. L. (2016). Conspiracy theories in the United States: More commonplace than extraordinary. Critical Review, 28(1), 127-136. https://doi.org/10.1080/08913811.2016.1172802.

Newheiser, A.-K., Farias, M., \& Tausch, N. (2011). The functional nature of conspiracy beliefs: Examining the underpinnings of belief in the Da Vinci code conspiracy. Personality and Individual Differences, 51(8), 1007-1011. https://doi.org/10.1016/j.paid.2011.08.011.

NPR. (2019). Brazilian Judge Acquits Man Who Stabbed Jair Bolsonaro. https://www.npr.org/2019/06/15/733032255/brazilian-judgeacquits-man-who-stabbed-jair-bolsonaro.

Painter, M., \& Qiu, T. (2020). Political beliefs affect compliance with COVID-19 social distancing orders. Available at SSRN: https://ssrn. com/abstract=3569098 or https://doi.org/10.2139/ssrn.3569098.

Paiva, F. M. (2019). Uma teoria conspiratória vista por 1 milhão de brasileiros diz que Bolsonaro forjou o atentado. A trama, porém, suscita questões verdadeiras. Carta Capital. https://www. cartacapital.com.br/politica/a-faca-de-dois-gumes/.

Pasek, J., Stark, T. H., Krosnick, J. A., \& Tompson, T. (2015). What motivates a conspiracy theory? Birther beliefs, partisanship, liberal-conservative ideology, and anti-black attitudes. Electoral Studies, 40, 482-489. https://doi.org/10.1016/j.electstud.2014.09. 009.

Pennycook, G., McPhetres, J., Bago, B., \& Rand, D. G. (2020). Predictors of attitudes and misperceptions about COVID-19 in Canada, the U.K., and the U.S.a. PsyArXiv Preprints [Preprint]. https://doi.org/10.31234/osf.io/zhjkp.

Mitchell, A., Jurkowitz, M., Oliphant, J. B, \& Shearer, E. (2020). Three Months In, Many Americans See Exaggeration, Conspiracy Theories and Partisanship in COVID-19 News. Pew Research Center. https://www.journalism.org/2020/06/29/three-months-inmany-americans-see-exaggeration-conspiracy-theories-andpartisanship-in-covid-19-news/\#.

Philips, T. \& Briso, C. (2020). Bolsonaro's anti-science response to coronavirus appalls Brazil's governors. The Guardian. https://www. theguardian.com/world/2020/mar/27/jair-bolsonaro-coronavirusbrazil-governors-appalled.

Radnitz, S., \& Underwood, P. (2015). Is belief in conspiracy theories pathological? A survey experiment on the cognitive roots of extreme suspicion. British Journal of Political Science, 47(1), 113-129. https://doi.org/10.1017/S0007123414000556.

Rydgren, J. (2005). Is extreme right-wing populism contagious? Explaining the emergence of a new party family. European Journal of Political Research, 44, 413-437. https://doi.org/10. 1111/j.1475-6765.2005.00233.x.

Saxena, S. (2020). Fake news, hiding data and profits: How COVID-19 spun out of control in Brazil. The Wire. https://thewire.in/health/ brazil-jair-bolsonaro-covid-19.

Shahsavari, S., Holur, P., Tangherlini, T, R., \& Roychowdhury, V, P. (2020). Conspiracy in the time of Corona: Automatic detection of Covid-19 conspiracy theories in social media and the news. ArXiv [Preprint]. https://arxiv.org/abs/2004.13783.

Sheeran, P., \& Webb, T. L. (2016). The intention-behavior gap. Social and Personality Psychology Compass, 10(9), 503-518. https://doi. org/10.1111/spc3.12265.

Smallpage, S. M., Enders, A. M., \& Uscinski, J. E. (2017). The partisan contours of conspiracy theory beliefs. Research \& Politics., 4 , 205316801774655. https://doi.org/10.1177/2053168017746554. 
Stempel, C., Hargrove, T., \& Stempel III, G. H. (2007). Media use, social structure, and belief in 9/11 conspiracy theories. Journalism \& Mass Communication Quarterly, 84(2), 353-372. https://doi.org/10.1177/ 107769900708400210

Sturgis, P., \& Allum, N. (2004). Science in society: Re-evaluating the deficit model of public attitudes. Public Understanding of Science, 13(1), 55-74. https://doi.org/10.1177/0963662504042690.

Sutton, R. M., \& Douglas, K. (2014). Examining the monological nature of conspiracy theories. In: van Prooijen, Jan Willem and van Lange, Paul A. M., eds. Power, politics, and paranoia: Why people are suspicious of their leaders. Cambridge: Cambridge University Press.

Swami, V., Coles, R., Stieger, S., Pietschnig, J., Furnham, A., Rehim, S., \& Voracek, M. (2011). Conspiracy beliefs in Britain and Austria: Evidence of a monological belief system and associations between individual psychological differences and real-world and fictitious conspiracy theories. British Journal of Psychology, 102, 443-463. https://doi.org/10.1111/j.2044-8295.2010.02004.x.

Taylor, S. (2019). The psychology of pandemics: Preparing for the next global outbreak of infectious disease. Newcastle upon Tyne, UK: Cambridge Scholars Publishing.

Tollefson, J. (2020). Brazilian lawmakers in showdown to double science budget. Nature. https://doi.org/10.1038/d41586-020-02433-y.
Van Prooijen, J.-W., \& Douglas, K. M. (2017). Conspiracy theories as part of history: The role of societal crisis situations. Memory Studies, 10(3), 323-333. https://doi.org/10.1177/1750698017701615.

Van Prooijen, J.-W., \& Douglas, K. M. (2018). Belief in conspiracy theories: Basic principles of an emerging research domain. European Journal of Social Psychology, 48, 897-908. https://doi. $\operatorname{org} / 10.1002 /$ ejsp. 2530.

Van Prooijen, J.-W., \& Jostmann, N. B. (2013). Belief in conspiracy theories: The influence of uncertainty and perceived morality. European Journal of Social Psychology, 43, 109-115. https://doi. org/10.1002/ejsp.1922.

Van Prooijen, J.-W., Krouwel, A. P. M., \& Pollet, T. V. (2015). Political extremism predicts belief in conspiracy theories. Social Psychological and Personality Science, 6(5), 570-578. https://doi. org/10.1177/1948550614567356.

Wood, M. J., Douglas, K. M., \& Sutton, R. M. (2012). Dead and alive: Beliefs in contradictory conspiracy theories. Social Psychological and Personality Science, 3(6), 767-773. https://doi.org/10.1177/ 1948550611434786.

Publisher's Note Springer Nature remains neutral with regard to jurisdictional claims in published maps and institutional affiliations. 